Conclusions: Anti-DFS70 is a valuable biomarker, with a very low prevalence in $S A D$, which gives it a role as a negative predictive marker of developing SAD when it is appears alone. Its detection in serum with a dense fine speckled pattern ANA (IFI) should be part of the protocol of the immunology laboratory. It is a cost-effective determination, as demonstrated in a recent study, by avoiding the costs associated with the follow-up of these patients. In our case, its finding allowed us to reassure the patient and avoid the accomplishment of further complementary tests, as well as an unnecessary monitoring.

Disclosure of Interest: None declared

DOI: 10.1136/annrheumdis-2017-eular.3410

\section{AB1017 THE DEFEAT OF THE HIP JOINT IN ANKYLOSING SPONDYLITIS BY MAGNETIC RESONANCE IMAGING}

E. Agafonova ${ }^{1,1}$, T. Dubinina, A. Dyomina, O. Rumiantceva, D. Rumiantceva, M. Podryadnova, A. Starkova, S. Krasnenko, M. Urumova, S. Erdes. Laboratory seronegative spondyloarthritis, Nasonova Research Institute of Rheumatology, Moscow, Russian Federation

Background: According to the carried out epidemiological studies in Russia of patients with ankylosing spondylitis (AS) defeat of the hip joints was impairment in $46 \%$ of cases, but was the reason for the replacement in $7 \%$ of cases. $i$

Objectives: To compare the clinical manifestations of hip arthritis (coxitis) with the results of magnetic resonance imaging (MRI) of the hip joints $(\mathrm{HJ})$ in patients with ankylosing spondylitis (AS).

Methods: Examined 117 patients (mean age $31,7 \pm 12.7$ y meeting modified $N-Y$ criteria), with complaints of pain in the hip joints. The average age of onset of disease was $26.3 \pm 20.3$ years, HLA-B27 identified in $93 \%$ of patients. The median duration of AS - 57 [2-384] months. BASDAI 5,7 $\pm 3,1$. Diagnosis of hip septic arthritis were made based on clinical signs - the presence of pain in hips and/or restriction of movements in $\mathrm{HJ}$ at the time of patient admission to the clinic. In addition to clinical and radiographic examination all patients were performed MRI modes T1 and STIR.

Results: The Median duration of clinical manifestations of coxitis by the time of the study was 60 months. [25\%; $75 \%$ ], evaluation of pain in $\mathrm{HJ}$ for numeric rating scaler (NRS) - 4 [2; 8]. According to MRI identified the following inflammatory changes (IC): synovitis-71 (83\%) patients, bone marrow edema (BME)- $44(31,6 \%)$ patients (BME acetabulum $36 \%$, BME heads $63 \%$ ), a combination of synovitis and BME were 7 patients $(9 \%)$. Depending on radiological stage (estimated by BASRI hip), patients were divided into two groups (table 1).

Results:

\begin{tabular}{|c|c|c|c|}
\hline Parameters & $\begin{array}{c}\text { Group (1) } \\
\text { BASRI hip 0-I }(n=48)\end{array}$ & $\begin{array}{c}\text { Group (2) } \\
\text { BASRI hip II-IV }(\mathrm{n}=60)\end{array}$ & $\mathrm{P}$ \\
\hline Gender (w/m), $\mathrm{n}$ & $20 / 28$ & $33 / 36$ & $0,04^{\star}$ \\
\hline AS duration,mo, Me $[25 \%, 75 \%]$ & $43[19 ; 80]$ & $102[24 ; 120]$ & $0,006^{\star}$ \\
\hline BASDAI, Me $[25 \%, 75 \%$ o] & $4,1[2,6 ; 5,5]$ & $5,6[4,2 ; 6,7]$ & $0,003^{*}$ \\
\hline BASFI, Me $[25 \%, 75 \%$ ] & $2,8[2,0 ; 3,8]$ & $3,3[2,0 ; 5,4]$ & $0,2^{*}$ \\
\hline HLA-B27, n (\%) & $96(91 \%)$ & $84(91 \%)$ & $0,7^{\star}$ \\
\hline ASDAS (CRP) Me $[25 \%, 75 \%]$ & $2,8[2,0 ; 3,8]$ & $3,5[2,6 ; 3,8]$ & $0,002^{*}$ \\
\hline $\mathrm{ESR}, \mathrm{mm} / \mathrm{h}, \mathrm{Me}[25 \%, 75 \%$ o] & $10[5 ; 25]$ & $25[8 ; 35]$ & $0,001^{*}$ \\
\hline $\mathrm{CRP}, \mathrm{mg} / \mathrm{mL}, \mathrm{Me}[25 \%, 75 \%]$ & $10,5[3,8 ; 28,5]$ & $23,0[4,9 ; 43,5]$ & $0,06^{*}$ \\
\hline NRS, Me $[25 \%, 75 \%]$ & $5[3 ; 6]$ & $6[4 ; 7]$ & $0,01^{\star}$ \\
\hline MRI Synovitis n (\%) & $44(92 \%)$ & $27(45 \%)$ & $0,003^{*}$ \\
\hline Osteitis n (\%) & $6(12,5 \%)$ & $38(64 \%)$ & $0,0001^{\prime}$ \\
\hline
\end{tabular}

Conclusions: MRI allows to clarify the cause of the pain and limitations of movement in $\mathrm{HJ}$ with AS, determine the patient has inflammatory changes, including in the absence of radiographic changes in these joints. Patients with severe radiological change (BASRI II-IV), have a greater duration of the disease, severe functional abnormalities in the BASFI index. With increasing radiological stage (BASRI hip II-IV) increased the detection rate of osteitis by MRI. Further research to clarify the relationship of clinical manifestations of coxitis (pain level) from MRI data.

Disclosure of Interest: None declared

DOI: 10.1136/annrheumdis-2017-eular.4985

\section{AB1018 DETECTION OF ANTI-DFS70 ANTIBODIES BY INDIRECT IMMUNOFLUORESCENCE (IIF) ON NOVEL HEP-2/DFS70-KO SUBSTRATE FOR DISCRIMINATING ANTINUCLEAR ANTIBODIES (ANA) - POSITIVE HEALTHY INDIVIDUALS (HI) AND PATIENTS WITH SYSTEMIC LUPUS ERYTHEMATOSUS (SLE)}

E. Aleksandrova, Z. Verizhnikova, A. Novikov, T. Panafidina, T. Popkova. V.A. Nasonova Research Institute of Rheumatology, Moscow, Russian Federation

Background: Autoantibodies against intracellular antigens are a serological hallmark of ANA-associated systemic autoimmune rheumatic diseases (AARD) such as SLE. IIF on HEp-2 cells for ANA remains the "gold standard" but it has very low positive predictive value. Up to $20 \%$ of serum samples from $\mathrm{HI}$ have been reported to have a positive ANA IIF test, the majority of them due to the presence of anti-dense fine speckled 70 (anti-DFS70) antibodies. Monospecific
anti-DFS70 antibodies represent a biomarker that can be used to discriminate AARD patients (pts) from HI in ANA IIF positive subjects. Recognition of the DFS70 ANA IIF pattern can be challenging. The DFS-KO Hep-2 cells inhibit anti-DFS70 antibodies reactions, providing clear differentiation of the DFS pattern from classical ANA patterns.

Objectives: To evaluate the utility of a novel HEp-2/DFS70-KO IIF substrate for the detection of anti-DFS70 antibodies in HI and SLE pts.

Methods: We studied $45 \mathrm{HI}$ (36 F/9 M; age 50.4 [24.0-72.0] years, median [interquartile range $25-75 \%$ ]) and 12 pts with SLE (ACR criteria, 1997) (10 F/2M, age 38.9 [17.0-65.0] years; disease duration 100.3 [4.0-432.0] months; SLEDAI $2 \mathrm{~K}$ score 11.7 [2-30]; SLICC damage index score 1.28 [0-4]). Serum samples were tested for classical ANA and anti-DFS70 antibodies by IIF technique with a mixture of standard HEp-2 cells and DFS70-KO HEp-2 cells ("Trinity Biotech", Bray, Ireland) as a substrate. Fluorescence titers $\geq 1$ : 160 were considered as positive for ANA patterns.

Results: ANA were present in $7 / 45(15.6 \%)$ of $\mathrm{HI}$ and in $12 / 12(100 \%)$ of SLE pts. All SLE pts and $3 / 45(6.7 \%)$ of HI showed classic ANA patterns (homogeneous, speckled, and mixed) in the absence of DFS70 pattern. $4 / 45(8.9 \%)$ of $\mathrm{HI}$ had classic ANA negative/anti-DFS70 antibodies positive IIF results. Isolated anti-DFS70 antibodies were found in $57 \%$ of ANA IIF positive HI. Among HI classic ANA and anti-DFS70 antibodies were detected in the low- to medium-titer range (1:1601:320). The frequency of anti-DFS70 antibodies did not correlated with age. Conclusions: The detection of isolated anti-DFS70 antibodies may be regarded as an exclusion criterion for the diagnosis of SLE. The testing for anti-DFS70 antibodies in a single step by HEp-2/DFS70-KO IIF method should be included into a modified ANA diagnostic algorithm. Additional investigations are required to evaluate the clinical relevance of anti-DFS70 autoantibodies.

Disclosure of Interest: None declared

DOI: 10.1136/annrheumdis-2017-eular.4008

\section{AB1019 ASSOCIATION OF INFLAMMATORY DISEASES - A CURRENT TOPIC FOR THE PRACTITIONER}

A. Cardoneanu ${ }^{1,2}$, A. Burlui ${ }^{1,2}$, C. Cijevschi Prelipcean ${ }^{3}$, E. Rezus ${ }^{1,2}$

${ }^{1}$ Rheumatology, University of Medicine and Pharmacy "Gr.T.Popa";

${ }^{2}$ Rheumatology Clinic, Rehabilitation Hospital; ${ }^{3}$ Gastroenterology, University of Medicine and Pharmacy "Gr.T.Popa", iasi, Romania

Background: Autoimmune, infectious, traumatic or neoplastic inflammation represents a warning for the practitioner. Numerous clinical specialties face daily with the presence of inflammation. The efforts of medical staff aim to establish the pathogenesis, the expansion and to find the most effective ways of treatment. Objectives: Our study objective is to highlight the correlations between Spondylarthropathies $(\mathrm{SpA})$ and intestinal manifestations, the link between the antigen HLA B27 and joint and intestinal inflammatory changes and also the relationship between the presence of sacroilitis and bowel disorders.

Methods: The study included 42 patients ( 28 men, 14 women). Of the 42 patients, 31 were diagnosed with ankylosing spondylitis (AS) (according to modified New York criteria), 8 with psoriatic arthritis (PSA) (using CASPAR diagnosis criteria) and 3 patients had had reactive arthritis (ReA) (according to ASAS criteria). All subjects enrolled in the study were screened for the presence of the antigen HLA-B27. Sacroiliitis was highlighted through pelvis X-ray centered on the SI joints. All patients diagnosed with AS presented radiological sacroiliitis, only 5 cases in the group of PsA and 1 patient diagnosed with ReA. To investigate the presence of intestinal inflammation, a colonoscopy with biopsy was performed to all subjects included in the study. Among patients with AS, 5 of them had inflammatory changes suggestive of Crohn's disease (CD) and 2 for ulcerative colitis (UC). Subclinical intestinal inflammation was evidenced in 15 cases: 12 of SA group and 3 of PsA group. We also highlighted 7 cases of irritable bowel syndrome: 1 patient with PsA and 6 patients with SA.

Results: After the statistical analysis of the collected data, the following statistically significant correlations were found $(p<0.05)$ : radiological sacroilitis correlated with AS and PsA; the antigen HLA-B27 is in close relation with all 3 forms of spondylarthritis; subclinical intestinal inflammation was positively correlated with AS and PsA. No associations were found between the presence of intestinal inflammation and sacroilititis.

Conclusions: This study points the link between intestinal and joint inflammation, primarily due to a common pathogenic mechanisms. A careful monitoring and a close collaboration between gastroenterologists and rheumatologists contributes to an optimal management of these patients.

References:

[1] Baeten D, de Keyser F, Mielants H, Veys EM. Ankylosing spondylitis and bowel disease. Best Pract Res Clin Rheumatol Sep 2002;16(4):537-549.

[2] Salmi M, Jalkanen S. Human leukocyte subpopulations from inflamed gut bind to joint vasculature using distinct sets of adhesion molecules. J Immunol 2001;166:4650-4657.

[3] May E, Marker-Hermann E, Wittig BM, Zeitz M, Meyer zum Buschenfelde $\mathrm{KH}$, Duchmann R. Identical T-cell expansions in the colon mucosa and the synovium of a patient with enterogenic spondyloarthropathy. Gastroenterology 2000;119:1745-1755.

[4] Peeters $H$, vanderCruyssen $B$, vander Cruyssen $B$, Mielants $H$, de Vlam K, Vermeire $\mathrm{S}$, et al. Clinical and genetic factors associated with sacroiliitis in Crohn's disease. J Gastroenterol Hepatol Jan 2008;23(1):132-137. 
[5] de Vlam K, Mielants H, Cuvelier C, de Keyser F, Veys EM, de Vos M. Spondyloarthropathy is underestimated in inflammatory bowel disease: prevalence and HLA association. J Rheumatol Dec 2000;27(12):2860-2865.

Disclosure of Interest: None declared

DOI: 10.1136/annrheumdis-2017-eular.2228

\section{AB1020 MULTIFREQUENCY BIOIMPEDANCE COMBINED WITH ACOUSTIC MYOGRAPHY - A NON-INVASIVE PAIN-FREE ASSESSMENT OF MUSCLE USE}

E.M. Bartels, J. Kvistgaard Olsen, H. Bliddal, L.E. Kristensen,

B. Danneskiold-Samsøe. The Parker Institute, Department of Rheumatology, Copenhagen University Hospital, Bispebjerg and Frederiksberg, Frederiksberg, Denmark

Background: Musculoskeletal diseases may involve muscle function, which often deteriorates due to a combination of pain and lack of exercise. Possible correction of this by training, or at least achievement of optimal efficiency of involved muscles with therapy, taking age and affecting disease into account, is an area which needs easily applicable and non-invasive pain-free assessment methods capable of monitoring daily living tasks outside a strict laboratory setting. Multi-frequency bioimpedance ( $\mathrm{mfBIA}$ ), assessing muscle health prior to exercise, in combination with Acoustic Myography (AMG), which allows real-time tests while e.g. walking or bicycling, may be such a method.

Objectives: To validate AMG combined with mfBIA for muscle-use assessment during a series of daily activity movements and exercise with the aim of introducing the method in the clinic.

Methods: 10 healthy subjects aged 25-68 years were assessed with mfBIA (Impedimed, Brisbane, Australia) prior to and following exercise of $\mathrm{m}$. gastrocnemius during walking, stair climbing and descending, and cycling with increasing load. AMG was recorded with a CURO unit (MyoDynamik ApS, Frederiksberg, Denmark), and data handling was carried out with the software belonging to the devices. The mfBIA parameters considered were resistance $(R)$, internal $(R i)$ and external $(\mathrm{Re})$ resistance and centre frequency (fc), and the AMG parameters were Efficiency $(E)$ - synchronization of motoric units, Temporal summation $(T)$ - how frequently do you use a particular muscle fibre, and Spatial summation (S) - how many fibres in use at a given time, all given as Median; Min,Max.

Results: The mfBIA data, showing the health state of the muscle, showed changes in $\mathrm{R}, \mathrm{Ri}, \mathrm{Re}$ and fc as expected for a healthy muscle as an effect of exercise. The AMG data showed good reproducibility with repeated measurements. Walking on flat ground was less synchronized $(E 2 ; 1,4)$ as were walking up $(E 4 ; 1,6)$ and down stairs $(E 3 ; 1,6)$, than cycling $(E 8.5 ; 5,9)$. With increasing load during cycling, $E$ decreased with the higher demand to $E 5.5$ range 1-7. The T-score was similar around 7 for all types of walking, while overall decreasing with increasing load during cycling from 6.5 to 5.5. The S-score was low during the three types of walk, indicating use of many fibres ( $S$ around 3 ), which is in line with the low E-score. For cycling the S-score decreased slightly with increasing load, from 8 to 7.5 . Conclusions: The combined method of mf-BIA and AMG shows good reproducibility. This method has the potential to assess training possibilities in patients with musculoskeletal diseases by testing directly on muscles during the movements of daily function. The method is applicable in real life settings outside the laboratory.

Acknowledgements: The Parker Institute is supported by the OAK Foundation Disclosure of Interest: None declared

DOI: 10.1136/annrheumdis-2017-eular.3369

\section{AB1021 VIDEOCAPILLAROSCOPIC FINDINGS IN PATIENTS WITH SYSTEMIC LUPUS ERYTHEMATOSUS WITH OR WITHOUT JACCOUD'S ARTHROPATHY}

C. Lins ${ }^{1}$, E.P.D. Fonseca ${ }^{2}$, D.L.D.S. Ribeiro ${ }^{2}$, W.G.D. Santos ${ }^{2}$, G. Rosa ${ }^{2}$, V. Machicado ${ }^{2}$, A.L. Pedreira ${ }^{2}$, A.P.M.D. Souza ${ }^{2}$, C. Baleeiro ${ }^{2}$, L.G.D.S. Ferreira ${ }^{2}$, I.S.D. Oliveira ${ }^{3}$, J.P.C.G.D. Silva ${ }^{3}$, A.M. Atta $^{3}$, M.B. Santiago ${ }^{2} .{ }^{1} E B M S P$ - Escola Bahiana de Medicina e Saude Publica ${ }^{2}$ EBMSP - Escola Bahiana de Medicina e Saude Publica; ${ }^{3}$ HUPES - Hospital Universitario Edgard Santos, Salvador, Bahia, Brazil

Background: Systemic lupus erythematosus (SLE) is an autoimmune disease that can present, as other collagen vascular disorders, changes in blood vessels. It can be evaluated by a non-invasive technique called periungual nailfold videocapillaroscopy (VCP). This technique is helpful in the diagnosis of systemic sclerosis (SSc), being part of the new classification criteria, and identifies individuals with Raynaud's phenomenon who are at a higher risk for developing SSc.

Objectives: This study aims to describe the videocapillaroscopic profile of a series of SLE patients and investigate if the VCP pattern is different among those with Jaccoud's arthropathy (JA) compared to the patients without this complication

Methods: The patients were submitted to VCP, clinical evaluation, and laboratory tests. The capillaroscopic patterns were defined as minor, major and scleroderma (SD). The presence of capillaroscopic findings such as elongated capillaries, increased tortuosity, ectasia, prominent venous plexus, neoangiogenesis, hemorrhage and megacapillaries was also observed.

Results: In a population of 113 female patients with SLE (67 without JA and 46 with JA), at least one alteration was observed in VCP in $89.40 \%$ of patients, and the "nonspecific changes" were the most prevalent. Minor changes were seen in $39(58.2 \%)$ and $26(56.5 \%)$ patients, and major changes were seen in $21(31.3 \%)$ and $11(23.9 \%)$ patients without and with JA, respectively. The SD patterns were observed in $02(3.0 \%)$ and $03(6.5 \%)$ patients without and with JA, respectively $(p>0.05)$.

Conclusions: The majority of patients of SLE present changes in the VCP exam, but such a tool does not allow distinguish those with or without JA.

References:

[1] Lambova SN, Muller-Ladner U. Capillaroscopic pattern in systemic lupus erythematosus and undifferentiated connective tissue disease: what we still have to learn? Rheumatology international. 2013;33(3):689-95.

[2] Ingegnoli F. Capillaroscopy abnormalities in relation to disease activity in juvenile systemic lupus erythematosus. Microvascular research. 2013;87:92-4. Santiago MB, Galvao V. Jaccoud arthropathy in systemic lupus erythematosus: analysis of clinical characteristics and review of the literature. Medicine. 2008;87(1):37-44

[3] Ingegnoli F, Zeni S, Meani L, Soldi A, Lurati A, Fantini F. Evaluation of nailfold videocapillaroscopic abnormalities in patients with systemic lupus erythematosus. Journal of clinical rheumatology: practical reports on rheumatic \& musculoskeletal diseases. 2005;11(6):295-8.

[4] Ragab O, Ashmawy A, Abdo A, Mokbel A. Nailfold capilloroscopy in systemic lupus erythematosus. The Egyptian Rheumatologist. 2011;33:61-7.

Acknowledgements: M. B.S. has received a scholar ship from Conselho Nacional de Desenvolvimento Científico e Tecnológico (CNPq).

Disclosure of Interest: None declared

DOI: 10.1136/annrheumdis-2017-eular.6627

\section{AB1022 THE RECALL SURVEY: THE RELATIONSHIP BETWEEN ULTRASOUND SYNOVITIS AND BONE EROSION IN PATIENTS} WITH RHEUMATOID ARTHRITIS

E. Filippucci ${ }^{1}$, C. Bonali ${ }^{2}$, P. Macchioni ${ }^{3}$, A. Iagnocco ${ }^{4}$, A. Delle Sedie ${ }^{5}$ S. Tropea ${ }^{6}$, O. Epis ${ }^{7}$, M. Canzoni ${ }^{8} .{ }^{1}$ Clinica Reumatologica, Università Politecnica delle Marche, Ancona; ${ }^{2}$ Rheumatology Unit, Ospedale San Paolo, Bari; ${ }^{3}$ Rheumatology Unit, Reggio Emilia Hospital, Reggio Emilia: ${ }^{4}$ Academic Rheumatology Unit, Università degli Studi di Torino, Torino; ${ }^{5}$ Rheumatology Unit, Università di Pisa, Pisa; ${ }^{6}$ ASP7, Busacca Hospital, Ragusa; ${ }^{7}$ Rheumatology Unit, Ospedale Niguarda Milano, Milano; ${ }^{8}$ Local Health Unit (ASL) Rome-1, Rome, Italy

Background: Ultrasound (US) has shown to be a sensitive imaging tool for the detection of subclinical signs of synovitis in patients (pts) with rheumatoid arthritis (RA); further studies are still required to delineate the impact of US findings in the management of RA pts in daily clinical practice.

Objectives: To investigate the relationship between US findings indicative of joint inflammation and US bone erosions at joint level in pts with RA.

Methods: In 2015 an educational event focused on the added value of US in RA pts was held in 22 rheumatology centers in Italy. In every center, the local rheumatologists provided RA pts to be examined by US. Pts signed an informed consent and a brief history of them was collected by the local rheumatologists (previous and current therapy, DAS28, HAQ score). Bilateral US examinations of wrists, metacarpophalangeal (MCP) and metatarsophalangeal (MTP) joints were performed by rheumatologists expert in US, to assess synovitis (joint effusion, synovial proliferation, and power Doppler (PD) signal), and bone erosions, using a Logiq E R7, General Electrics, with a 4.2-13 MHz linear probe. All US findings were scored using a 4 degree semiquantitative scoring system.

Results: In 465 RA pts, a total of 10.230 joints were scanned. Of these joints, 3.969 (39\%) showed joint effusion and/or synovial proliferation and $1.784(17 \%)$ were found positive for PD signal. The most frequently involved joints were the wrists followed by the second MCP joints and first MTP joints. In 749 joints US detected at least one bone erosion. The most frequently eroded joints were the wrists, the second and fifth MCP joints and the first and fifth MTP joints. A total of 226 RA pts showed at least one bone erosions and in $181(80 \%)$ of these pts the eroded joints were found positive for PD signal.

Conclusions: A high prevalence of PD signal was found in the joints found eroded by US. This is the first study providing such an evidence using a portable US equipment.

Disclosure of Interest: None declared

DOI: 10.1136/annrheumdis-2017-eular.4286

\section{AB1023 QUANTIFERON ${ }^{\circledR}$-TB GOLD IN-TUBE ASSAY CAN BE USED FOR LATENT TUBERCULOSIS SCREENING BEFORE BIOLOGICAL DRUG TREATMENT IN A BCG VACCINATED COUNTRY: HUR-BIO SINGLE CENTER REAL LIFE RESULTS}

E. Seyhoğlu ${ }^{1}$, O.A. Uyaroğlu ${ }^{1}$, A. Erden ${ }^{2}$, L. Kılıç ${ }^{2}$, B. Armağan ${ }^{2}$, A. Sarı ${ }^{2}$, M. Baykal ${ }^{2}$, S. Ak ${ }^{2}$, Ö. Karadağ ${ }^{2}$, A. Akdoğan ${ }^{2}$, S. Apraş Bilgen ${ }^{2}$, S. Kiraz ${ }^{2}$, I. Ertenli ${ }^{2}$, U. Kalyoncu ${ }^{2} .{ }^{1}$ Department of Internal Medicine; ${ }^{2}$ Division of Rheumatology, Department of Internal Medicine, Hacettepe University School of Medicine, Ankara, Turkey

Background: Patients treated with biologic agents have increased risk of 